\title{
Bagaimana meningkatkan school wellbeing? memahami peran school connectedness pada siswa SMA
}

\author{
Ulifa Rahma ', Faizah', Yuliezar Perwira Dara ${ }^{3}$, Najwa Wafiyyah ${ }^{4}$ \\ 1,2,3,4 Program Studi Psikologi, Universitas Brawijaya
}

\begin{tabular}{l}
\hline Info Artikel \\
\hline Sejarah Artikel: \\
Diterima \\
08 Agustus 2019 \\
Direview \\
02 Oktober 2019 \\
Disetujui \\
08 Februari 2020 \\
Dipublikasikan \\
27 Februari 2020 \\
\hline Keywords: \\
school connectedness, \\
school well-being, \\
secondary school
\end{tabular}

\begin{abstract}
Abstrak
Objektif: penelitian ini dilakukan untuk melihat pengaruh school connectedness dengan school well-beng siswa Sekolah Menengah Atas.

Metode: penelitian ini merupakan penelitian kuantitatif yang terdiri dari siswa SMA sebanyak 134 orang berdasarkan perhitungan aplikasi G*Power versi 3.I.9.2. Pengambilan data dilakukan dengan cara membagikan 2 skala yaitu skala school connectedness dan skala school well being dengan menggunakan metode accidental sampling. Uji analisis data dalam penelitian ini menggunakan pearson product moment.
\end{abstract}

Temuan: hasilnya ialah terdapat hubungan positif dengan $(r=0.77, p=0.00)$ yang berarti terdapat hubungan antara variabel school connectedness dengan school well being pada siswa Sekolah Menengah yang signifikan. Hasil penelitian ini memiliki nilai yang positif dimana terdapat hubungan positif antara variabel yaitu semakin tinggi tingkat school connectedness siswa terhadap sekolahnya maka semakin tinggi pula tingkat school well beingnya, dan sebaliknya.

Kesimpulan: dimensi school connectedness yang berpengaruh terhadap school wellbeing adalah being connected and liked by students, communication dan being liked by teachers. Namun untuk dimensi belonging tidak memiliki pengaruh terhadap school wellbeing pada siswa SMA. Dimensi school connectedness yang memiliki effect size terbesar adalah being liked by teachers kemudian communication dan yang terakhir adalah being connected and liked by students.

\section{The predictor of bullying in elementary students}

Objectives: this research was conducted to look at the relationship between school and school - both in high school students.

\begin{abstract}
Method: this research is a quantitative study involving subjects consisting of 134 high school students based on the calculation of the application $G *$ Power version 3.1.9.2. Data retrieval is done by connecting two scales, namely the scale of school connectivity and school scale using the accidental sampling method. Test data analysis in this study using Pearson product moment.
\end{abstract}

Findings: There was positive relationship between school connectedness and school wellbeing variables in the Middle School students is significan $(r=0.77, p=0.00) t$. The results of this study have a positive value. Where there is a positive relationship between variables, the higher the level of student school connection to the school, the higher the school level will be, and vice versa.

Conclusions: dimensions of school connectedness related to school wellbeing are related and liked by students, communication and liked by teachers. But belonging does not have an influence on school wellbeing in high school students. The dimension of school connectednes which has the greatest effect size is liked by the teachers then communication and the last is connected and liked by students.

\footnotetext{
*Alamat korespondensi:

Program Studi Psikologi, Universitas Brawijaya, Jl. Veteran, Ketawanggede, Kec. Lowokwaru, Malang ulifa.rahma@ub.ac.id
} 


\section{Pendahuluan}

Siswa yang berada pada usia Sekolah Menengah masuk dalam masa remaja pertengahan. Menurut Santrock (2014) masa remaja pertengahan dalam rentang usia 15-18 tahun. Sekolah Menengah adalah sebuah institusi yang memberikan pendidikan sekunder yang merupakan lanjutan dari pendidikan dasar 6 tahun. Tujuan dari sekolah Menengah adalah untuk meningkatkan pengetahuan dan untuk mengembangkan diri sejalan dengan perkembangan ilmu pengetahuan, teknologi dan kesenian. Tujuan yang kedua ialah meningkatkan kemampuan siswa sebagai anggota masyarakat dalam mengadakan hubungan timbal balik dengan lingkungan sosial, budaya, dan alam sekitarnya (Ahmad, 2010).

Berdasarkan tujuan Sekolah Menengah pada pasal diatas sejalan dengan pendapat Papalia, Olds, \& Feldman (2009) yaitu sekolah merupakan sarana yang potensial dalam membentuk kepribadian individu serta konsep sosial yang baik sehingga sekolah akan memberikan rasa sejahtera terhadap siswa. Sekolah memberikan dampak pada sejumlah aspek kehidupan dan perkembangan remaja, seperti identitas diri, keyakinan akan kemampuan diri, gambaran mengenai kehidupan, hubungan antar pribadi, batasan norma antara hal yang baik dan buruk serta konsep sistem sosial. Maka dari itu keberadaan sekolah sangat penting bagi perkembangan setiap individu terlebih pada remaja Sekolah Menegah. Pada masa sekarang, pendidikan merupakan aspek yang penting karenapendidikan menyiapkan remaja dalam pemilihan karir di masa depan. Sekolah adalah sebuah institusi pendidikan formal yang disediakan oleh pemerintah yang saat ini tidak hanya memiliki fungsi sebagai tempat menuntut ilmu saja, melainkan juga sebagai tempat pembentukan moral, karakter, pengembangan minat dan bakat siswa (Santrock, 2014).

Apabila sekolah dianggap sehat, maka akan memberikan perasaan senang dan membentuk sikap dan penilaian yang positif dari siswa (Konu \& Rimpela, 2002). Apabila siswa di sekolah mengalami kejenuhan, maka siswa merasa tidak memiliki hubungan sosial yang baik dengan orang lain di sekolahnya dan menyebabkan pemenuhan dirinya di sekolah seperti terabaikan (Rizki \& Listiara, 20I5). Pemenuhan diri baik kebutuhan material dan non material di lingkungan sekolah berkaitan dengan school well being.

School well being ialah penilaian yang berisifat subjektif oleh siswa terhadap bagaimana sekolahnya yang akan memenuhi kebutuhan dasarnya. Dimensi kebutuhan dasar tersebut ialah having, loving, being, dan health (Konu \& Rimpela, 2002). Having adalah kondisi atau keaadaan dari tempat belajar meliputi lingkungan di dalam dan disekitar sekolah. Loving ialah hubungan siswa dengan lingkungannya, termasuk lingkungan sosialnya, hubungannya dengan siswa lainnya, dinamika kelompok serta hubungan antara lingkungan rumah dengan sekolahnya, kemudian being adalah kemungkinan seorang siswa dapat belajar sesuai dengan minatnya, kemampuannya dan kebiasaannya dan yang terakhir health yaitu ketiadaan penyakit yang muncul karena dampak dari proses belajar (Konu \& Rimpela, 2002).

Beberapa faktor yang dapat mempengaruhi school well being siswa menurut Keyes dan Waterman (2008) yaitu hubungan sosial, teman dan waktu luang, sukarelawan, peran sosial, karakteristik kepribadian, kontrol diri dan sikap optimis, serta tujuan dan aspirasi. Terdapat faktor hubungan sosial dari beberapa faktor tersebut, dimana hubungan sosial adalah kegiatan yang menghubungkan kepentingan antar inidividu, individu dengan kelompok, ataupun antar kelompok baik itu secara langsung atau tidak yang menciptakan rasa menguntungkan dan kerjasama. Hubungan sosial erat kaitannya dengan school connectedness. Lester, Waters \& Cross (2013) menjelaskan bahwa school connectedness meningkatkan wellbeing siswa ketika berada disekolah. Ketika siswa memiliki keterhubungan dengan sekolah mereka lebih mungkin terlibat dan menunjukkan kontribusi di sekolah dalam kegiatan ekstrakurikuler dan bahagia, mampu meningkatkan harga diri, memiliki keterampilan mengatasi masalah yang lebih baik, memiliki dukungan sosial sehingga siswa mampu meningkatkan school wellbeing yang dimiliki dengan merasa nyaman dengan lingkungan belajar disekolahnya, mampu membangun hubungan sosial secara baik dengan lingkungan sekolah dan teman temannya, serta mampu meningkatkan keberhasilan akademis karena merasa mampu mengembangkan diri sesuai dengan bakat dan minatnya sehingga secara fisik juga merasa sehat karena merasa nyaman dengan proses belajar selama disekolah. Adanya school connectedness 
membuat siswa merasa wellbeing disekolah dan membentuk ikatan yang positif sehinggga berpengaruh terhadap keberhasilan akademis siswa. Lemberger \& Clemens, 2012). Namun, kurangnya school connectedness akan berpengaruh pada kurangnya wellbeing siswa disekolah sehingga memiliki dampak negatif pada kemajuan akademik siswa (Peguero et al., 2016).

School connectedness sendiri didefinisikan oleh Sugar (2012) sebagai keterhubungan seorang siswa terhadap sekolahnya, tidak hanya dinilai dari rasa kepemilikan terhadap sekolahnya, tetapi juga keterhubungan dengan elemen yang ada di sekolah yang akan mempengaruhi suasana sekolah dari siswa tersebut. School connectedness mempunyai 4 dimensi, yaitu being connectedness and liked by student, belonging, communication, dan being liked by teacher.

Siswa lebih cenderung terlibat dalam perilaku sehat dan berhasil secara akademis ketika mereka merasa terhubung ke sekolah (Blum, 2009). Lohmeier \& Lee (20II) memaparkan ketika siswa merasa tidak mempunyai hubungan baik terhadap sekolahnya, maka mereka bisa jadi akan terlibat dalam perilaku negatif. Sebaliknya apabila siswa mempunyai school connectedness yang tinggi terhadap sekolahnya, mereka akan mendapatkan peringkat tinggi di akademiknya, dekat dengan teman-teman sebayanya, terlibat pada kegiatan akademik, dan sejahtera emosionalnya (Lohmeier \& Lee, 20II).

Pada penelitian Keyes \& Waterman (2008) individu yang lebih sering terlibat dalam hubungan sosial yang baik serta memiliki peran sosial yang baik pula akan memiliki tingkat kepuasan dalam hidup yang lebih tinggi. Studi lebih lanjut menunjukkan peran sosial individu di lingkungan tempat dirinya berada dapat meningkatkan well-being dan menurunkan tingkat stress yang dimiliki dari penelitian tersebut, siswa yang memiliki hubungan sosial yang baik dengan elemen yang ada di sekolahnya akan meningkatkan well beingnya. Begitupun sebaliknya, apabila siswa memiliki hubungan sosial yang kurang baik, maka akan berdampak dengan buruknya level well beingnnya. Keyes \& Waterman (2008) menjelaskan bahwa individu yang mendapatkan dukungan dari teman akan lebih merasakan kebahagiaan dan kesejahteraan di sekolahnya. Hal ini didukung oleh pendapat Santrock (2014) yang mengungkapkan bahwa teman sebaya merupakan sumber status, persahabatan dan rasa saling memiliki yang penting dan dibutuhkan dalam situasi sekolah.

Menurut Niehaus, Irvin, dan Rogelberg (2016), sekolah adalah konteks lingkungan utama bagi siswa dan pembelajaran mereka, pengembangan hubungan positif di sekolah dengan school connectedness sangat penting untuk mempromosikan school wellbeing sehingga berdampak pada hasil akademik yang positif. Blum (2009) menjelaskan bahwa sekolah selain merupakan tempat untuk mendapatkan pendidikan juga tempat yang membangun kehidupan para generasi muda lebih baik serta mencapai kesuksesan. Selain itu dijelaskan bahwa siswa akan lebih mungkin untuk mencapai kesuksesan ketika siswa merasakan bahwa mereka merupakan "milik" sekolah dan memiliki rasa "keterhubungan" pada sekolah atau disebut juga memiliki school connectedness. Sebaliknya, apabila siswa mengalami kejenuhan, maka ia akan merasa tidak memiliki hubungan sosial yang baik dan pemenuhan dirinya di sekolah terasa seperti diabaikan, apabila pemenuhan dirinya di sekolah terabaikan maka school well beingnya tidak terpenuhi.

Berdasarkan paparan diatas, school connectedness dan school well being mempunyai hubungan yang sangat berpengaruh kepada kualitas sekolah yang ada di Indonesia. Maka dari itu penulis mengangkat judul hubungan school connectedness dan school well being pada siswa SMA.

\section{Metode}

Variabel Bebas (independent) dalam penelitian ini adalah school connectedness dan variabel terikat (Dependent) adalah School well being. School well being adalah penilaiaan siswa secara subjektif terkait sekolahnya dalam proses pemenuhan kebutuhan dasar dari siswa tersebut di sekolahnya. School well being mempunyai 4 dimensi, yaitu havingterkait dengan kondisi sekolahnya, being terkait dengan pemenuhan dirinya, loving terkait dengan hubungan siswa dengan orang -orang di sekolahnya, dan health terkait dengan kondisi kesehatan siswa. School connectedness adalah keadaan 
dimana siswa merasa telah dihormati, diterima dan merasa menjadi bagian, serta mendapatkan dukungan dari orang lain dalam lingkungan sosial sekolahnya, baik itu guru-gurunya, temantemannya dan staff yang ada di sekolahya. School connectedness mempunyai 4 dimensi yaitu being connected and like by student yaitu merasa terhubung, dihormati dan disukai oleh siswa lainnya yang menciptakan rasa percaya diri dan aman di sekolah, kemudian dimensi kedua ialah belonging yaitu rasa kepemilikan terhadap sekolah, dimensi ketiga ialah communication yaitu adanya komunikasi yang baik siswa dengan guru dan staff yang berada di sekolah dan dimensi yang terakhir ialah being liked by teachers yaitu hubungan yang positif antar siswa dan gurunya.

Populasi pada penelitian ini adalah siswa sekolah menengah. Pada penelitian ini sampel yang ditentukan ialah siswa SMA yang memiliki rentang usia 15 - 18 tahun dan berjumlah 134 orang subjek berdasarkan dari aplikasi Gpower versi 3.I dengan power 0.95, dan error prob 0.05. Sampling yang digunakan pada penelitian ini ialah accidental sampling yaitu teknik penentuan sampel berdasarkan kebetulan, atau siapa saja yang secara kebetulan bertemu dengan peneliti yang layak digunakan sebagai sampel atau dipandang cocok sebagai sumber data. Dalam penelitian ini yaitu siswa SMA yang memiliki rentang usia 15 - 18 tahun.

Instrumen yang akan digunakan dalam penelitian ini ialah skala school connectedness dan skala school well being. Skala yang digunakan pada variabel school connectedness ini ialah skala measurement of school connectedness MOSC) oleh Irina Sugar (2012) yang telah diadaptasi oleh peneliti kedalam bahasa Indonesia. Dimana keempat dimensi pada MOSC yaitu being connected and liked by students, belonging, communication telah diuji reliabilitasnya menggunakan Cronbach's Alpha, dan menghasilkan nilai sebesar 0.68 hingga 0.87 . Skala yang digunakan pada variabel school well being ini ialah skala yang telah diadaptasi dari skala school well being profile oleh (Konu \& Rimpela, 2002) ke bahasa Indonesia oleh peneliti. Konsistensi internal dari empat dimensi skala school well being menunjukkan cronbach's alpha senilai 0.84 (having) 0.62 (loving) 0.8 I (being) dan 0.8 I (health).

Dalam penelitian ini, peneliti melakukan adaptasi skala dari dua variabel yang diangkat, yaitu skala school well beingdari Konu \& Rimpela (2002) dan skala school connectedness dari Sugar (2012). Adaptasi alat ukur ialah kegiatan menentukan apakah alat ukur yang digunakan dapat mengukur konstruk yang sama dalam bahasa dan budaya yang berbeda, kemudian memilih penerjemah, dan memutuskan apa akomodasi yang sesuai, sampai mengecek kesetaraannya dalam bentuk yang diadaptasi (Hambleton, Marenda, \& Spielberger, 2005). Bahasa asli dari kedua skala tersebut menggunakan bahasa inggris dan diterjemahkan kedalam bahasa Indonesia oleh pusat bahasa FIB UB dan oleh translator UM, kemudian skala dengan bahasa Indonesia tersebut digabungkan dan diterjemahkan kembali ke bahasa inggirs. Seluruh skala yang terdiri dari skala asli berbahasa inggris, 2 skala berbahasa Indonesia, gabungan skala berbahasa Indonesia dan skala berbahasa inggris terakhir diserahkan kepada 3 orang expert judgement yaitu 3 orang dosen yang berkompeten dalam bidang tersebut. Hasil dari ketiga expert judgement tersebut disatukan agar bisa menjadi satu skala yang telah diadaptasi.

Diskriminasi item dilakukan untuk mengetahui seberapa jauh item yang telah disusun berfungsi bagi alat ukur. Diskriminasi item ini dilakukan kepada skala school well being dan skala school connectedness dengan melihat correlated item total correlation. Skala yang akan digunakan dalam penelitian ini terlebih dahulu di ujicoba (try out) dengan memberikaan skala tersebut kepada subjek yang masuk dalam populasi penelitian yang tidak dijadikan sebagai sampel dalam penelitian. Pelaksanaan try out atau uji coba tersebut menggunakan 30 siswa, yang dimana jumlah sampel untuk uji coba skala minimal 30 orang. Sampel diambil dari 30 orang siswa kelas I0-MIA SMA AIizzah, kemudian didilakukan uji analisis item menggunakan software IBM SPSS statistic 24 for windows. Pada try out atau uji coba yang telah dilaksanakan, skala school connectedness menggunakan batasan rix $>0,20$. Skala tersebut berjumlah 24 item dan seluruh itemnya berhasil lolos.

Skala school well being pada awalnya mempunyai 78 item, kemudian gugur sejumlah I5 item, I item dari dimensi having yaitu item nomor 4, kemudian 3 item dari dimensi being yaitu item nomor 42, 43,57 , selanjutnya II item gugur dari dimensi health yaitu item nomor $68,69,70,7 \mathrm{I}, 72,73,74$, 75, 76, 77 dan 78. Seluruh item (II item) dari dimensi health gugur, dan tidak menyisakan satupun 
item, maka dari itu diambil kembali 3 item dengan nilai rix tertinggi syarat kembali memperbaiki redaksional kata dari dimensi health tersebut. 3 item tersebut ialah item nomor 7l dengan nilai rix 0.10 kemudian item nomor 76 dengan nilai 0.54 , dan yang terakhir ialah item 77 dengan nilai 0.83 . Setelah 3 item dari dimensi health dimasukkan dan direvisi bahasanya, skala memiliki 66 total item yang siap dimasukkan kedalam skala yang akan digunakan untuk melaksanakan penelitian.

Reliabilitas merupakan sebuah pengukuran yang dapat menghasilkan data dengan tingkat reliabilitas yang tinggi (Azwar, 20l4). Pada penelitian ini digunakan analisis reliabilitas Cronbach's Alpha pada program IBM SPSS statistic 24 for windows. Hasilnya menunjukkan bahwa nilai Cronbach's Alpha dari variabel school connectedesss senilai 0.933 yang dimana reliabilitas skala school conncectedness termasuk dalam kategori sangat tinggi $(0.80-1.00)$ dengan jumlah total item yang lolos adalah 24 item dari 24 item juga. Kemudian pada skala variabel school well being mempunyai hasil Cronbach'sAlpha yaitu 0.972 dan termasuk dala kategori sangat tinggi pula, dengan jumlah item yang lolos sebesar 65 item dari total jumlah 78 item. Dari hasil tersebut telah ditunjukkan bahwa kedua skala tersebut layak untuk dijadikan sebagai alat ukur dalam penelitian ini.

Metode analisis data yang akan digunakan pada penelitian ini ialah uji asumsi dan uji hipotesis. menggunakan metode pearson product moment correlation, yang dimana akan terlihat hubungan antara kedua variabel yang digunakan.

\section{Hasil}

Deskripsi subjek yang digunakan didalam penelitian ini diperoleh melalui dimana kategorisasi jenis kelamin laki-laki sebanyak 75 anak dengan prosentase $55.97 \%$ dan jenis kelamin perempuan sebanyak $6 \mathrm{I}$ anak dengan prosentase $44.8 \%$. Kemudian untuk kategorisasi usia, rentang usia subjek ialah 14-18 tahun dengan rata-rata usia ialah 15.8 tahun.

Analisis data deskriptif bertujuan untuk memberikan suatu deskripsi terhadap subyek penelitian berdasarkan data dari membandingkan perhitungan dari data hipotetik dengan data empiric (data di lapangan). Kemudian hasil dari perbandingan tersebut dikategorikan berdasarkan berdasarkan tingkatan tinggi, sedang atau rendah. Perhitungan data empirik diperoleh menggunakan SPSS for windows versi 20.0 dan data hipotetik diperoleh dari perhitungan manual oleh peneliti.Skor empirikdiperoleh berdasarkan data dilapangan kemudian dianalisis dengan SPSS for windows versi 20.0. Skor hipotetik diperoleh dari perhitungan manual. Berikut tabel perbandingan hasil antara data skor hipotetik dan skor empiric dari variabel school connectedness dan variabel school well being.

Tabel I.

Perbandingan Data Hipotetik dengan Data Empirik

\begin{tabular}{|c|c|c|c|c|c|c|c|c|c|}
\hline \multirow[b]{2}{*}{ Variabel } & \multirow[b]{2}{*}{$\mathrm{N}$} & \multicolumn{4}{|c|}{ Data Empirik } & \multicolumn{4}{|c|}{ Data Hipotetik } \\
\hline & & $\begin{array}{l}\text { Nilai } \\
\text { Min }\end{array}$ & $\begin{array}{l}\text { Nilai } \\
\text { Max }\end{array}$ & Mean & $\begin{array}{l}\text { Std } \\
\text { Dev }\end{array}$ & $\begin{array}{l}\text { Nilai } \\
\text { Min }\end{array}$ & $\begin{array}{l}\text { Nilai } \\
\text { Max }\end{array}$ & Mean & $\begin{array}{l}\text { Std } \\
\text { Dev }\end{array}$ \\
\hline $\begin{array}{l}\text { School } \\
\text { Connectedness }\end{array}$ & 136 & 46.00 & 94.00 & 70.82 & 7.87 & 24 & 96 & 60 & 12 \\
\hline SchoolWell Being & & 128.00 & 442.00 & 307.96 & 55.26 & 0 & 264 & 132 & $4 I$ \\
\hline
\end{tabular}

Berdasarkan tabel I dapat diketahui bahwa hasil skor empirik dari variabel school connectedness mempunyai nilai minimal 46.00, nilai maksimal 94.00, dengan mean 70.82 dan standar deviasi sebesar 7.87. Kemudian pada variable school well being mempunyai nilai minimal sebesar 128.00 , nilai maksimal sebesar 442.00, dengan mean sebesar 307.96 danstandar deviasi sebesar 55.26. 
Kemudian tabel diatas menunjukkan hasil nilai hipotetik yang menggunakan perhitungan manual dari variabel school connectedness dan school well being. Dapat disimpulkan bahwa skor hipotetik variabel school connectedness mempunyai nilai minimum sebesar 24, nilai maksimal 96 , dengan mean 60 dan standar deviasi sebesar 12. Kemudian pada variabel school well being mempunyai nilai minimal sebesae 0 , nilai maksimal sebesar 264, dengan mean sebesar 132 dan standar deviasi sebesar $4 \mathrm{I}$.

Kemudian tahapan selanjutnya ialah menentukan kategorisasi variabel yang bertujuan untuk mengelompokkan individu atau subjek penelitian berdasarkan atribut yang diukur. Kategorisasinya meliputi rendah, sedang dan tinggi (Azwar, 2013). Kategorisasi variabel berdasarkan kategori hipotetik. Berikut table hasil kategorisasi variabel dan rentang skornya :

Tabel 2.

Hasil Kategorisasi variabel

\begin{tabular}{lllll}
\hline Variabel & Rentang skor & Kategori & Jumlah subjek & Persentase \\
\hline \multirow{3}{*}{ School connectedness } & $X<48$ & Rendah & I & $0.7 \%$ \\
& $48 \leq X<72$ & Sedang & 80 & $59.7 \%$ \\
& $X \geq 72$ & Tinggi & 53 & $39.6 \%$ \\
School well being & $X<91$ & Rendah & 0 & $0 \%$ \\
& $91 \leq X<173$ & Sedang & I & $0.7 \%$ \\
& $X \geq 173$ & Tinggi & 133 & $99.3 \%$ \\
\hline
\end{tabular}

Berdasarkan tabel hasil kategorisasi variabel diatas diketahui bahwa variabel school connectedness mempunyai responden yang termasuk rendah berjumlah I orang dengan presentase $0.7 \%$, kategori sedang berjumlah 80 orang dengan presentase $59.7 \%$, dan kategori tinggi berjumalah 53 orang dengan presentase $39.6 \%$. Kemudian pada variabel school well being responden dengan kategori rendah berjumlah 0 atau tidak ada dengan presentasi $0 \%$, selanjutnya kategori sedang berjumlah I orang dengan presentasi sebesar $0.7 \%$ dan kategori tinggi berjumlah 133 orang dengan presentasi $99.3 \%$.

Maka dari itu dapat disimpulkan pada variabel school connectedness dengan responden berada pada kategori sedang dengan presentasi $59.7 \%$, dan pada vaariabel school well being responden berada pada kategori tinggi dengan presentasi $99.3 \%$.

Uji asumsi menggunakan Uji normalitas dan linearitas. Uji normalitas dilakukan untuk membuktikan apakah populasi data yang telah didistribusi sudah normal atau tidak. Uji normalitas ini menggunakan metode kolmogrov-smirnov yang akan dikategorikan normal apabila nilai signifikansi $\alpha$ sebesar 0.05 atau lebih dari 0.05 (Azwar, 2005). Berdasarkan hasil uji normalitas kolmogrov-smirnov diperoleh hasil uji dengan nilai signifikansi sebesar $0.72(p>0.05)$ sehingga dapat disimpulkan bahwa data didalam penelitian ini terdistribusi secara normal. Uji linieritas bertujuan untuk mengetahui apakah variabel school connectedness memiliki hubungan yang linier dengan variabel school well being. Uji linearitas ini dilakukan menggunakan SPSS for windowsversi 20.0. Data yang telah diperoleh bisa dikatakan berhubungan secara linier apabila memiliki nilai sig $>0.05$. Hasil uji linearitas antara variabel School connectedness dan school well being memiliki nilai signifikansi 0.1 I yang dimana nilai tersebut lebih besar dari 0.05 , maka dari itu hasil tersebut menunjukkan bahwa variabel School connectedness memiliki hubungan yang linier dengan variabel school well being.

Berdasarkan uji hipotesis yang telah dilakukan oleh peneliti terhadap variable school connectedness dengan school well being pada siswa SMA tampak bahwa terdapat hubungan yang positif antara dua variable tersebut. Uji hipotesis tersebut dilakukan menggunakan korelasi pearson product moment dan hasilnya dapat dilihat pada tabel dibawah ini. 


\section{Tabel 3.}

\section{Hasil dari Uji Hipotesis}

\begin{tabular}{llll}
\hline Variabel & Koefisien korelasi & Signifikan & keterangan \\
\hline $\begin{array}{l}\text { School connectedness dan school } \\
\text { well being }\end{array}$ & 0.77 & 0.00 & Korelasi kuat \\
\hline
\end{tabular}

Dari tabel 3 dapat dilihat bahwa terdapat hubungan karena $(p<0.05)$, yaitu $(0.00<0.05)$. Dapat disimpulkan bahwa hipotesis $(\mathrm{Ha})$ dalam penelitian ini dapat diterima, yaitu terdapat hubungan antara variabel school connectedness dengan school well being pada siswa SMA yang signifikan. Kemudian dilihat dari nilai koefisien korelasi dapat menentukan kekuatan hubungan antara dua variabel tersebut, 0.77 dapat dikategorisasikan kedalam korelasi kuat antaraschool connectedness dengan school well being pada siswa SMA.

Nilai korelasi pearson product moment yang dihasilkan bernilai positif $(0.77)$ yang dimana nilai tersebut menunjukkan adanya suatu hubungan yang positif antara variabel school connectedness dengan school well being. Yaitu semakin tinggi tingkat school connectedness yang dimiliki siswa terhadap sekolahnya, maka semakin tinggi pula tingkat school well beingnya. Kemudian sebaliknya semakin rendah tingkat school connectedness yang dimiliki siswa terhadap sekolahnya, maka semakin rendah juga tingkat school well being siswa tersebut.

Tabel 4.

Nilai regresi masing-masing dimensi school connectedness

\begin{tabular}{cccc}
\hline Sumber & $R$ & $R^{2}$ & Sig \\
\hline $\begin{array}{c}\text { Being connected and liked by } \\
\text { students }\end{array}$ & 0.33 & 0.10 & 0.00 \\
\hline Belonging & 0.66 & 0.43 & 0.10 \\
\hline Communication & 0.41 & 0.10 & 0.00 \\
\hline Being liked by teachers & 0.73 & 0.53 & 0.00 \\
\hline
\end{tabular}

Tabel 4 menunjukkan nilai regresi dimensi school connectedness yang berpengaruh terhadap school wellbeing adalah being connected and liked by students, communication dan being liked by teachers karena memiliki niai signifikansi $\leq 0.05$. Namun untuk dimensi belonging memiliki nilai signifikansi $0.10 \geq 0.05$, yang berarti tidak ada pengaruh dimensi belonging terhadap school wellbeing pada siswa SMA. Dari tabel di atas dapat dilihat bahwa dimensi school connectedness yang memiliki effect size terbesar adalah being liked by teachers $\left(R^{2}=0.73\right)$ kemudian communication $\left(R^{2}=0.41\right)$, dan yang terakhir adalah being connected and liked by students $\left(R^{2}=0.33\right)$.

\section{Pembahasan}

Tujuan utama dari penelitian ini ialah mengetahui apakah ada hubungan antara variabel school connectedness dengan variabel school well being pada siswa SMA. Berdasarkan hasil uji hipotesis yang telah dilakukan menggunakan analisis pearson correlation product moment nilai signifikansi sebesar 0.00 yaitu dibawah 0.5 yang berarti hipotesis $\mathrm{Ha}$ yang diajukan pada penelitian ini dapat diterima dan Ho dalam penelitian ini ditolak. Korelasi antar variabel dalam penelitian ini memiliki arah yang positif yaitu semakin tinggi school connectedness siswa pada sekolahnya maka semakin tinggi pula school well being siswa pada sekolahnya dan begitupun sebaliknya apabila semakin rendah level school connectedness yang dimiliki oleh siswa makin semakin rendah pula level school well beingnya.

Hal tersebut sesuai dengan pendapat Lohmeier dan Lee, (20II) apabila siswa mempunyai keterhubungan dengan sekolahnya (school connectedness) yang tinggi terhadap sekolahnya, mereka akan mendapatkan peringkat tinggi di akademiknya, dekat dengan teman-teman sebayanya, terlibat 
pada kegiatan akademik, dan sejahtera emosionalnya (Lohmeier \& Lee, 20II). Pencapaian peringkat tinggi dan keterlibatan dalam kegiatan di sekolah berhubungan dengan dimensi being pada school well being, dan sejahtera emosionalnya berkaitan dengan dimensi health pada school well being. Pendapat tersebut mendukung bahwa apabila school connectedness tinggi maka akan didukung dengan school well being yang tinggi pula. Sebaliknya, menurut Resnick (dalam Lohmeier \& Lee, 20II) ketika siswa merasakan tidak ada keterhubungan dengan sekolah atau kurangnya school connectedness terhadap sekolahnya, maka mereka bisa jadi akan terlibat dalam penggunaan obatobatan terlarang (narkoba), perilaku kasar, resiko tinggi terhadap perilaku internalisasi seperti percobaan bunuh diri dan gangguan makan. Penggunaan obat-obatan terlarang dan perilaku kasar masuk dalam minimnya fungsi pengawasan karena tidak mempunyai hubungan yang dekat terhadap guru dan orangtuanya yang masuk kedalam kurangnya dimensi loving dari school well being siswa. Kemudian, perilaku percobaan bunuh diri dan gangguan makan merupakan kurangnya dimensi health dari school well being yang dimiliki oleh siswa. Dari pernyataan diatas dapat disimpulkan bahwa semakin kurang level school connectedness pada siswa maka akan kurang pula level school well being yang dimilikiinya.

Adanya hubungan antar variabel school connectedness dengan variabel school well being juga sesuai dengan pendapat Keyes \& Waterman (2008) yang menjelaskan bahwa individu yang mendapatkan dukungan dari teman akan lebih merasakan kebahagiaan dan kesejahteraan di sekolahnya. Hal tersebut menunjukkan bahwa semakin individu atau siswa mempunyai dukungan atau hubungan yang baik dengan teman-temannya atau berada pada dimensi being connected and liked by students dari variabel school connectedness maka akan merasakan kebahagiaan dan kesejahteraan ketika siswa tersebut berada di sekolah, kesejahteraan merupakan school well being (Setyawan \& Dewi, 2015). Pendapat tersebut didukung pula oleh pendapat Resnick (1997) (dalam McNelly, Nonnemaker, \& Blum, 2002) yaitu ketika remaja merasa diperhatikan oleh orang lain di sekolah dan menjadi bagian dari sekolah mereka, maka mereka memiliki level well-being yang lebih tinggi Pernyataan tersebut menggambarkan apabila siswa diperhatikan oleh orang lain di sekolah, baik itu guru (sesuai pada dimensi being liked by teachers) dan siswa (pada dimensi being connected and liked by students) yang ada di sekolah tersebut, kemudian merasa menjadi bagian dari sekolah tersebut (sesuai pada dimensi belonging) maka siswa tersebut akan memiliki level well being yang tinggi.

Dimensi school connectedness yang paling memberikan peran terhadap school wellbeing adalah being like by teacher. Being liked by teachers ialah disukai oleh guru atau hubungan yang positif antar siswa dan gurunya. Peran guru dalam lingkungan pendidikan sangat penting, didukung oleh beberapa teori motivasi yang dianalisis melalui lensa dari teori school connectedness (Sugar, 2012). Kidger, Araya, Donovan, \& Gunnell, (20I2) mengungkapkan bahwa wellbeing siswa disekolah akan terbentuk ketika siswa mendapatkan dukungan guru. Wang (2009) menjelaskan dukungan guru yaitu sejauh mana guru mendukung, responsif, dan berkomitmen, apabila guru memberikan dukungan dan siswa merasa disukai oleh guru maka akan berpengaruh terhadap kesejahteraan siswa disekolah (school wellbeing). Sebuah studi kualitatif tentang hubungan guru-siswa menemukan bahwa pengembangan hubungan dekat, dengan diskusi yang lebih sering tentang topik yang jauh dari mata pelajaran akademik $d$ mendukung school wellbeing dan kesehatan mental siswa (Maelan, Tjomsland, Baklien, Samdal, \& Thurston, 2018).

Dimensi school connectedness selanjutnya yang memberikan peran terhadap school wellbeing adalah communication. Menurut Waters et. al., (2009) komunikasi ialah mendukung kesejahteraan siswa disekolah (school wellbeing). Siswa, guru dan staf sangat penting untuk dapat mengekspresikan diri, menghargai orang lain, mengapresiasi pekerjaan orang lain dan mengkomunikasikan apa saja kebutuhan mereka. Komunikasi dalam pengertian ini tidak terbatas pada kemampuan berbicara dengan orang lain, tetapi ditambah dengan perasaan aman, tidak dihakimi dan tidak dibatasi oleh rasa takut ketika berkomunikasi (Sugar, 2012).

Dimensi being like by student juga penting bagi siswa karena diusia ini adalah usia remaja. Selama periode ini, mereka berkomunikasi dengan teman-teman lebih dari orang tua mereka untuk memenuhi kebutuhan kepercayaan dan hubungan dekat (Smith, 20I5). Siswa juga menghabiskan 
banyak waktu disekolah dan untuk alasan ini mereka menghabiskan banyak waktu dengan temanteman mereka (Doğan, Karaman, Çoban \& Çok, (20I2). Penelitian tentang pentingnya pertemanan dan being like by student terkait dengan variabel adaptif psikologis (Akın, Akın \& Uğur, 2016). Dengan kata lain, memiliki persahabatan yang mendukung dan merasa disukai berkaitan dengan school well being (Chow, Ruhl \& Buhrmester, 2013; Rinn et al., 20II). Dimensi ini mencakup perasaan dihormati, disukai, dan terhubung dengan orang lain, yang akan memunculkan suasana positif dan ramah didalam lingkungan sekolah. Selain itu, definisi dari being connected and liked by students ialah perasaan diterima dan aman secara psikologis di sekolah (Sugar, 2012).

Dimensi yang tidak memberikan pengaruh terhadap school wellbeing adalah belonging. Belonging ialah rasa memiliki atau rasa bangga adalah hal yang berhubungan secara simbolik dengan dimensi yang telah dijelaskan sebelumnya (Sugar, 20I2). Lavigne, Vallerand, dan Crevier-Braud (20II) yang menemukan belonging dapat diuraikan sehubungan dengan dua orientasi yang berbeda dalam valensi: orientasi pertumbuhan (mirip dengan motif fokus-pendekatan) versus orientasi pengurangan-defisit ( mirip dengan motif yang berfokus pada penghindaran). Orientasi pertumbuhan mengacu pada minat mendasar dalam memperoleh hubungan interpersonal yang memuaskan. Belonging tidak memberikan peran secara terpisah dengan schoolwellbeing dapat dikarenakan bukan hal utama bagi siswa untuk mendapatkan hubungan interpersonal yang mamemuaskan. Bukan lebih pada memiliki rasa bangga atau memiliki, tapi lebih bagaimana individu menjadi lebih disukai oleh orang orang dilingkungan sekolahnya dan adanya komunikasi. Belonging memiliki peran secara simultan terkait dengan school wellbeing karena ketika individu mampu memiliki komunikasi yang baik, merasa disukai oleh orang orang dilingkungan sekolah diantaranya adalah guru, staff, teman, maka rasa bangga atau rasa memiliki terhadap sekolahnya juga berpengaruh dengan kesejahteraan disekolah karena ada dimensi lainnya tersebut.

Berdasarkan dari hasil kategorisasi variabel school connectedness ditemukan bahwa mayoritas siswa SMA yang menjadi subjek dalam penelitian ini mempunyai school connectedness dan school well being yang baik di sekolahnya. Terbukti dari tingkat school connectedness yang dimiliki oleh siswayang berada pada kategori sedang yaitu berjumlah 80 orang $(59.7 \%$,) dan yang berada pada kategori tinggi berjumlah 53 orang (39.6\%) kemudian tingkat school well being yang dimiliki oleh siswa yang berada pada kategori tinggi yaitu sebanyak 133 siswa dengan prosentase $99.3 \%$, hal tersebut menunjukkan bahwa school connectedness terbanyak yaitu pada kategori sedang dan tinggi kemudian school well being pada kategori tinggi.Hal tersebut didukung oleh pendapat blum yaituketika siswa merasa terhubung ke sekolah maka mereka akan lebih cenderung terlibat dalam perilaku sehat (dimensi health yang baik) dan berhasil secara akademis (umpan balik dari dimensi being) (Blum, 2009). Selain itu dijelaskan oleh Blum (2009), bahwa ketika siswa merasakan bahwa mereka merupakan "milik" sekolah dan memiliki rasa "keterhubungan" pada sekolah maka siswa akan lebih mungkin untuk mencapai kesuksesan.

\section{Kesimpulan}

Berdasarkan dari hasil penelitian yang telah dilakukan maka dapat disimpulkan bahwa terdapat hubungan yang positif antara school well being dengan school connectedness pada siswa SMA sehingga hipotesis $\mathrm{Ha}$ dapat diterima dan Ho ditolak, artinya semakin tinggi tingkat school connectedness siswa terhadap sekolahnya maka akan semakin tinggi pula tingkat school well beingnya, dan sebaliknya semakin rendah tingkat school connectedness siswa terhadap sekolahnya maka akan semakin rendah pula tingkat school well beingnya.

Implikasi dari penelitian ini untuk siswa SMA diharapkan dapat meningkatkan hubungannya dengan lingkungan sosialnya di sekolah, yaitu hubungan dengan siswa lainnya, dengan guru, serta meningkatkan dinamika kelompok ketika di sekolah, agar dapat meningkatkan aspek school connectedness terhadap sekolahnya. Siswa diharapkan meningkatkan rasa penerimaan diri terhadap sekolahnya agar bisa merasa sejahtera ketika berada di sekolah dan memiliki hubungan sosial yang 
baik dengan seluruh perangkat sekolah. Guru diharapkan mempunyai hubungan sosial yang baik dengan para siswa seperti memberikan memberikan dukungan, berlaku adil dan memberikan apresiasi karena akan mempengaruhi level school well being dan school connectedness para siswanya. Pihak sekolah diharapkan mampu memaksimalkan 3 aspek having sekolah yaitu lingkungan fisik, lingkungan belajar dan layanan sekolah. Lingkungan fisik meliputi peningkatan fasilitas lingkungan di dalam dan disekitar sekolah agar menjadi nyaman untuk belajar. Aspek kedua memperbaiki kondisi lingkungan belajar yang mencakup kurikulum, jadwal pelajaran, hukuman serta peraturan sekolah. Aspek terakhir ialah meningkatkan layanan siswa, yaitu meningkatkan fasilitas dari kantin, ruang unit kesehatan siswa (UKS)dan bimbingan konseling (BK).

Sekolah juga perlu mempromosikan pentingnya school connectedness agar dapat meningkatkan school wellbeing siswa disekolah dengan Menghormati keragaman, mendorong input siswa, kebijakan disiplin yang toleran, dan ukuran kelas kecil. Perlu juga untuk melibatkan orang tua dalam kehidupan akademik dan sekolah, dengan mengadakan pertemuan rutin untuk membahas peningkatan potensi baik prestasi non akademik dan prestasi akademik anak, menawarkan kelas untuk meningkatkan keterampilan orang tua mengurangi hambatan keterlibatan orang tua. Lebih lanjut, hubungan saling percaya dan peduli di antara staf sekolah, orang tua, siswa, dan masyarakat melalui berbagai metode seperti menciptakan pengalaman belajar bagi siswa untuk bekerja dengan orang dewasa (misalnya, magang, $\mathrm{KKN}$ ), mendorong staf untuk menyapa siswa dengan nama, dan membuka gedung sekolah untuk keluarga dan anggota masyarakat di luar jam sekolah untuk program rekreasi dan promosi kesehatan. Menerapkan strategi tersebut di lingkungan sekolah pada akhirnya dapat berdampak positif untuk memunculkan scholl connectedness yang akhirnya membuat siswa memiliki school wellbeing.

\section{REFERENSI}

Ahmad, J. N. (20I0). Penggunaan School Well Being pada Sekolah Menengah Atas (SMA) Bertaraf Internasional Sebagai Barometer Evaluasi Sekolah. Jurnal UI Untuk Bangsa Seri Sosial dan Humaniora, 102-103.

Akın, U., Akın, A., \& Uğur, E. (2016). Mediating role of mindfulness on the associations of friendship quality and subjective vitality. Psychological Reports, I/9(2), 516-526. doi: I0.1I77/0033294II666/273

Azwar, S. (2013). Metode Penelitian. Yogyakarta: Pustaka Pelajar.

Azwar, S. (2014). Reliabilitas Dan Validitas. Yogyakarta: Pustaka Pelajar.

Blum, R. (2009). School Connectedness: strategies for increasing protective factors among yoouth. U.S: Department of Health and Human Services.

Chow, C. M., Ruhl, H. \& Buhrmester, D. (2013). The mediating role of interpersonal competence between adolescents' empathy and friendship quality: A dyadic approach. Journal of adolescence, 36(I), I9I-200. doi:I0.1016/j.adolescence.2012.10.004

Doğan, T., Karaman, N. G., Çoban, A. E. \& Çok, F. (20I2). Predictors of adolescents' friendship qualities: gender and family related variables. Elementary Education Online, I I (3), 845-855.

Konu, A. I., \& Rimpela, T. P. (2002). Well Being in School : A conceptual model. Health Promotion International, 79-87.

Keyes, C. L. M. \& Waterman, M. B. (2008). Dimensions of well-being and mental health in adulthood. Dalam Marc H. Bornstein, dkk. (Ed), WellBeing: Positive development across the life course. New Jersey, NJ: Lawrence Erlbaum Associates, Inc.

Kidger J, Araya R, Donovan J, Gunnell D. (2012) The effect of the school environment on the emotional health of adolescents: A systematic review. Pediatrics, 129(5), 925-949. 
Lavigne GL, Vallerand RJ, Crevier-Braud L. (20II). The fundamental need to belong on the distinction between growth and deficit-reduction orientations. Personality and Social Psychology Bulletin, 37(9): I I85-1201.

Lemberger, M. E., \& Clemens, E. V. (2012). Connectedness and self-regulation as constructs of the student success skills program in inner-city African American elementary school students. Journal of Counseling \& Development, 90(4), 450-458. doi:I0.1002/j.I5566676.20I2.00056.x

Lester, L., Waters, S., \& Cross, D. (20/3). The relationship between school connectedness and mental health during the transition to secondary school: A path analysis. Australian Journal of Guidance and Counselling, 23(2), I57-I7I. doi:10.10I7/jgc.2013.20

Lohmeier, J. H., \& Lee, S. (20I I). A school Connectedness scale for use with adolescents. Educational Research and Evaluation, I7(2),, 85-95.

McNelly, C., Nonnemaker, J. M., \& Blum, R. W. (2002). Promoting school connectedness: evidence from the national longitudinal study of adolesence health. Journal of School Health, 284-292.

Maelan E. N., Tjomsland H. E., Baklien B., Samdal O., \& Thurston M. (2018). Supporting pupils' mental health through everyday practices: A qualitative study of teachers and head teachers. Pastoral Care in Education, 36(I), 16-24.

Niehaus, K., Irvin, M. J., \& Rogelberg, S. (2016). School connectedness and valuing as predictors of high school completion and postsecondary attendance among Latino youth. Contemporary Educational Psychology, 44, 54-67.

Papalia, Olds, \&Feldman. (2009). Human Development (I I th edition). NewYork: Mc graw Hill.

Peguero, A. A., Ovink, S. M., \& Li, Y. L. (2016). Social bonding to school and educational inequality race/ethnicity, dropping out, and the significance of place. Sociological Perspectives, 59(2), 3|7-344. doi:10.1 I77/073 | I2|4|5586479

Purbaya, A. A. (2018, Maret 02). Retrieved April 04, 2018, from Detik.com: https://news.detik.com/berita/

Rahayu, C. M. (2017, Maret 23). Detik News. Retrieved Maret 02, 20I8, from Detik.com: https://news.detik.com/berita

Rinn, A. N., Reynolds, M. J. \& McQueen, K. S. (20II). Perceived social support and the selfconcepts of gifted adolescents. Journal for the Education of the Gifted, 34(3), 367-396. doi:10.1177/016235321103400302

Santrock, J. W. (20I4). Psikologi Pendidikan: Educational Psychology (Buku 2) (Edisi 5). Jakarta: Salemba Humanika.

Setyawan, I., \& Dewi, K. S. (20I5). kesejahteraan sekolah ditinjau dari orientasi belajar mencari makna dan kemampuan empati siswa sekolah menengah atas. Jurnal Psikologi UNDIP, I4, 920.

Sugar, I. (2012, May). Measuremet of School Connectedness (MOSC), Modified Connectedness Questionnaire for Secondary School. Faculty of The USC Rossier School of Education University of Southern California , 39-40.

Wang, M.T. (2009). School climate support for behavioral and psychological adjustment: Testing the mediating effect of social competence. School Psychology Quarterly, 24(4), 240-25I. 